\title{
The GTS-QOL-French questionnaire
}

Les problèmes de santé peuvent affecter la qualité de vie d'une personne de différentes manières. Ce questionnaire étudie la manière dont votre maladie influe sur votre bien-être.

Merci de mettre une croix dans la case correspondant à la réponse la plus adaptée à votre ressenti.

Il est à noter que cette liste inclut de nombreux problèmes que vous ne rencontrerez probablement jamais.

\begin{tabular}{|c|c|c|c|c|c|}
\hline $\begin{array}{l}\text { Durant les quatre dernières } \\
\text { semaines avez-vous : }\end{array}$ & $\begin{array}{l}\text { Aucun } \\
\text { problème }\end{array}$ & $\begin{array}{l}\text { Problème } \\
\text { léger }\end{array}$ & $\begin{array}{l}\text { Problème } \\
\text { modéré }\end{array}$ & $\begin{array}{l}\text { Problème } \\
\text { important }\end{array}$ & $\begin{array}{l}\text { Problème } \\
\text { très } \\
\text { important }\end{array}$ \\
\hline $\begin{array}{l}\text { 1. été incapable de contrôler tous } \\
\text { vos mouvements? }\end{array}$ & Г & $\square$ & $\square$ & - & $\square$ \\
\hline $\begin{array}{l}\text { 2. eu des difficultés dans vos } \\
\text { activités de la vie quotidienne ou } \\
\text { vos loisirs (comme cuisiner, } \\
\text { écrire)? }\end{array}$ & 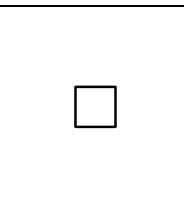 & & $\square$ & & \\
\hline $\begin{array}{l}\text { 3. souffert de douleurs ou de } \\
\text { blessures physiques secondaires à } \\
\text { vos tics? }\end{array}$ & $\square$ & $\square$ & $\square$ & $\square$ & $\square$ \\
\hline $\begin{array}{l}\text { 4. été gêné(e) par des bruits que } \\
\text { vous ne pouvez vous empêcher } \\
\text { de faire? }\end{array}$ & L & & $\leftarrow$ & & \\
\hline $\begin{array}{l}\text { 5. redouté de dire des gros mots } \\
\text { que vous n'aviez pas l'intention } \\
\text { de dire? }\end{array}$ & $\square$ & ᄂ & $\square$ & & $\square$ \\
\hline $\begin{array}{l}\text { 6. redouté de faire quelque chose } \\
\text { d'embarrassant (comme des } \\
\text { gestes grossiers)? }\end{array}$ & 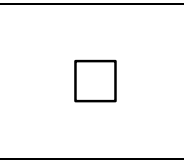 & & $\square$ & & \\
\hline $\begin{array}{l}\text { 7. été obligé(e) de répéter des } \\
\text { mots encore et encore ? }\end{array}$ & $\square$ & $\square$ & $\square$ & $\square$ & $\square$ \\
\hline $\begin{array}{l}\text { 8. été obligé(e) de refaire ou de } \\
\text { répéter des choses que d'autres } \\
\text { personnes font ou disent (imiter } \\
\text { les gens)? }\end{array}$ & 4 & & & & \\
\hline $\begin{array}{l}\text { 9. été obligé(e) de faire des } \\
\text { choses d'une manière répétée et } \\
\text { d'une certaine façon (comme } \\
\text { vérifier, toucher)? }\end{array}$ & ᄂ & & $\square$ & & $\square$ \\
\hline $\begin{array}{l}\text { 10. eu des pensées ou des images } \\
\text { déplaisantes vous passant par la } \\
\text { tête? }\end{array}$ & ᄂ & $\square$ & $\square$ & $\square$ & $\square$ \\
\hline $\begin{array}{l}\text { 11. eu des difficultés de } \\
\text { concentration? }\end{array}$ & $\square$ & $\square$ & $\square$ & $\square$ & $\square$ \\
\hline $\begin{array}{l}\text { 12. eu des problèmes de } \\
\text { mémoire? }\end{array}$ & $\square$ & $\square$ & $\square$ & $\square$ & $\square$ \\
\hline
\end{tabular}




\begin{tabular}{|c|c|c|c|c|c|}
\hline $\begin{array}{l}\text { 13. perdu ou égaré des } \text { objets } \\
\text { importants (comme un } \\
\text { portefeuille, des clefs, un } \\
\text { téléphone mobile)? }\end{array}$ & $\square$ & $\square$ & $\square$ & $\square$ & $\square$ \\
\hline $\begin{array}{l}\text { 14. eu des difficultés à finir ce } \\
\text { que vous avez commencé ? }\end{array}$ & $\square$ & $\square$ & $\square$ & $\square$ & $\square$ \\
\hline $\begin{array}{l}\text { 15. eu l'impression dans } \\
\text { l'ensemble d'être en mauvaise } \\
\text { santé ? }\end{array}$ & $\square$ & $\square$ & $\square$ & $\square$ & $\square$ \\
\hline 16. été triste ou déprimé ? & $\square$ & $\square$ & $\square$ & $\square$ & $\square$ \\
\hline $\begin{array}{l}\text { 17. ressenti des changements } \\
\text { d'humeur rapides? }\end{array}$ & $\square$ & $\square$ & $\square$ & $\square$ & $\square$ \\
\hline $\begin{array}{l}\text { 18. ressenti un manque de } \\
\text { confiance en soi ? }\end{array}$ & $\square$ & $\square$ & $\square$ & $\square$ & $\square$ \\
\hline 19. ressenti de l'angoisse? & $\square$ & $\square$ & $\square$ & $\square$ & $\square$ \\
\hline 20. ressenti de l'énervement? & $\square$ & $\square$ & $\square$ & $\square$ & $\square$ \\
\hline $\begin{array}{l}\text { 21. eu des difficultés à garder } \\
\text { votre calme? }\end{array}$ & $\square$ & $\square$ & $\square$ & $\square$ & $\square$ \\
\hline $\begin{array}{l}\text { 22. eu l'impression de ne pas } \\
\text { contrôler votre vie? }\end{array}$ & $\square$ & $\square$ & $\square$ & $\square$ & $\square$ \\
\hline 23. ressenti de la frustration? & $\square$ & $\square$ & $\square$ & $\square$ & $\square$ \\
\hline $\begin{array}{l}\text { 24. ressenti le besoin de plus } \\
\text { d'aide ou de soutien des autres? }\end{array}$ & $\square$ & $\square$ & $\square$ & $\square$ & $\square$ \\
\hline $\begin{array}{l}\text { 25. eu des difficultés à voir vos } \\
\text { amis? }\end{array}$ & $\square$ & $\square$ & $\square$ & $\square$ & $\square$ \\
\hline $\begin{array}{l}\text { 26. eu des difficultés à prendre } \\
\text { part à des activités sociales } \\
\text { (comme aller manger à } \\
\text { l'extérieur)? }\end{array}$ & $\square$ & $\square$ & $\square$ & $\square$ & $\square$ \\
\hline $\begin{array}{l}\text { 27. eu le sentiment d'être seul(e) } \\
\text { ou isolé(e)? }\end{array}$ & $\square$ & $\square$ & $\square$ & $\square$ & $\square$ \\
\hline
\end{tabular}

Merci d'indiquer à quel point vous vous sentez dans l'ensemble satisfait de votre vie en ce moment, en mettant une croix entre 0 et 100 sur la ligne ci-dessous.

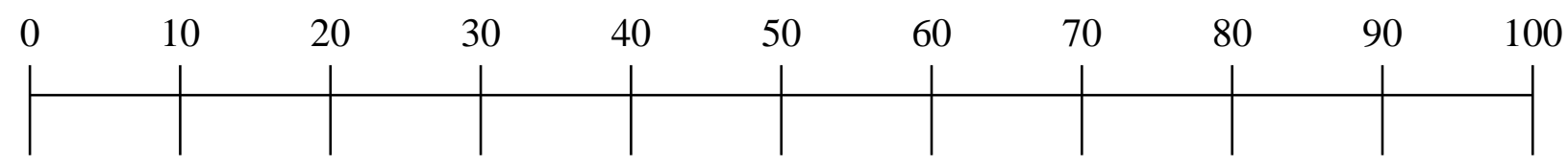

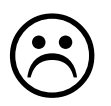

Extrêmement insatisfait de ma vie
Extrêmement satisfait de ma vie

Merci beaucoup d'avoir répondu à ce questionnaire ! 